\title{
Strategy of small-caliber endoscopic submucosal dissection for esophageal neoplasia distal to severe stricture
}

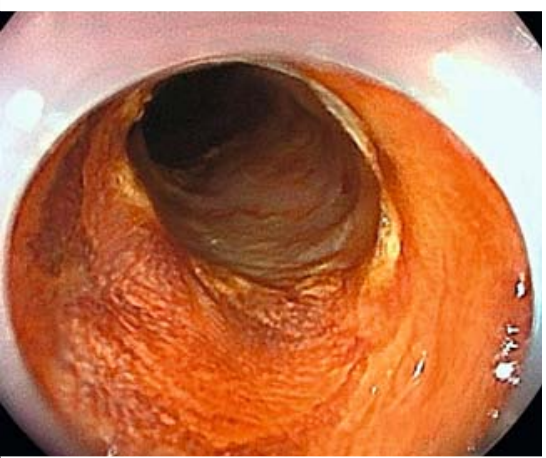

- Fig. 1 Early esophageal carcinoma distal to stenosis after previous endoscopic submucosal dissection of the upper thoracic esophagus. The stenosis prevents the passage of a conventional endoscope.

When esophageal neoplasia occurs distally to severe stenosis after prior endoscopic submucosal dissection (ESD) [1, 2], a conventional endoscope cannot pass through. Therefore, a small-caliber endoscope (SCE) must be used. Although transnasal ESD of a small esophageal lesion using an SCE without sedation has been reported [3], it is unclear whether an SCE is feasible for standard ESD with compatible devices. Herein, we report the first case of esophageal ESD using an SCE for a circumferential lesion located distally to severe stenosis.

Esophageal carcinoma occurred distally to stenosis after a previous ESD and prevented the passage of a conventional endoscope ( Fig. 1). After obtaining written informed consent, ESD using an SCE (EG-L580NM7; Fujifilm, Tokyo, Japan) [3] was performed under general anesthesia. Auxiliary devices included a transparent hood (Nanoshooter; Top Co., Tokyo, Japan) connected to a waterjet generator, electrosurgical unit (VIO3; ERBE Elektromedizin, Tübingen, Germany), and multifunctional snare (SOUTEN; Kaneka Medics, Tokyo, Japan) [4], with forced coagulation mode (effect 4, 40W) for marking, endocut mode (endocut Q) for circumferential cutting, and swift coagu-

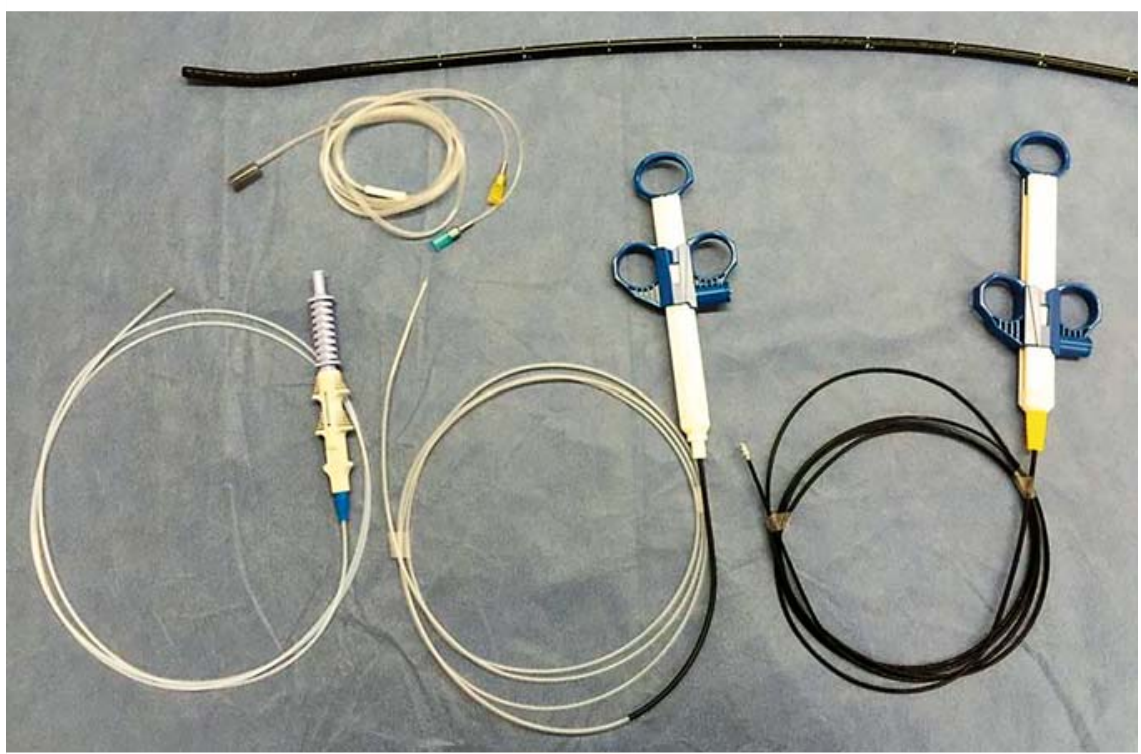

- Fig. 2 Endoscopic submucosal dissection under general anesthesia using a small-caliber endoscope (EG-L580NM7; Fujifilm, Tokyo, Japan) with a transparent hood (Nanoshooter, Top Co., Tokyo, Japan) connected to a waterjet generator, electrosurgical unit (VIO3; ERBE Elektromedizin, Tübingen, Germany), a multifunctional snare (SOUTEN; Kaneka Medics, Tokyo, Japan), and a 25-G needle (Super Glip, Top Co.) for local injection of hyaluronate sodium solution.

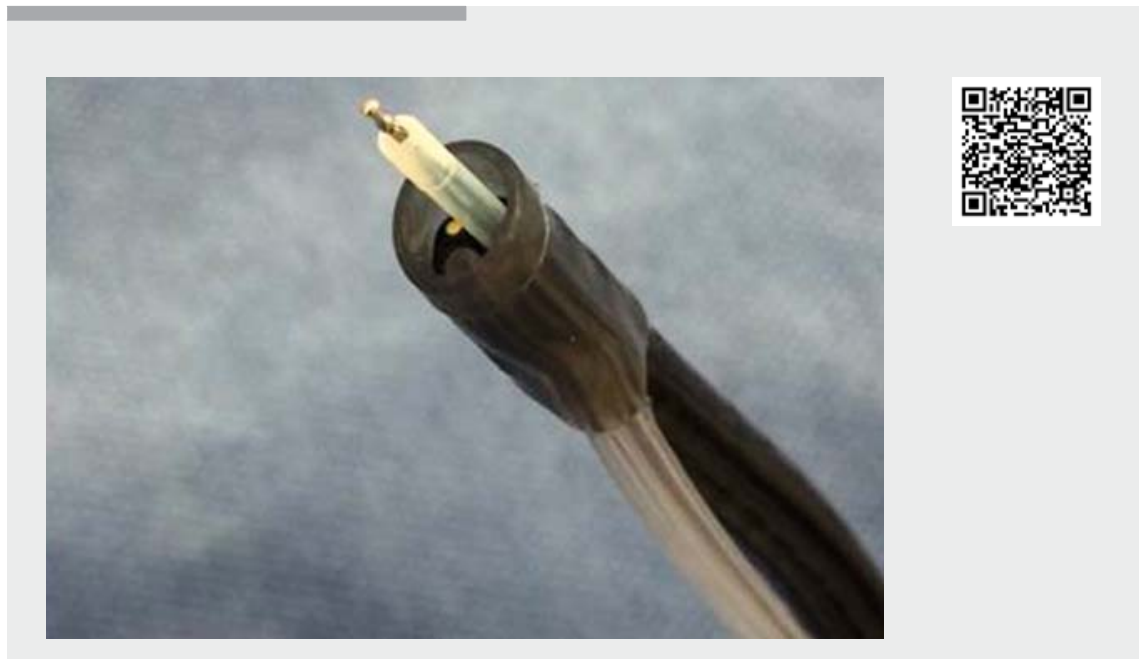

Video 1 Esophageal endoscopic submucosal dissection using a small-caliber endoscope with compatible devices for a circumferential lesion distal to severe stenosis.

lation mode (effect 4, 60 W) for submucosal dissection ( $\$$ Fig. 2 ). Hyaluronate sodium was injected locally via a $25-\mathrm{G}$ needle (Super Glip, Top Co.). Hemostasis was achieved with hemostatic forceps (RC1900; Kaneka Medics). Submucosal 


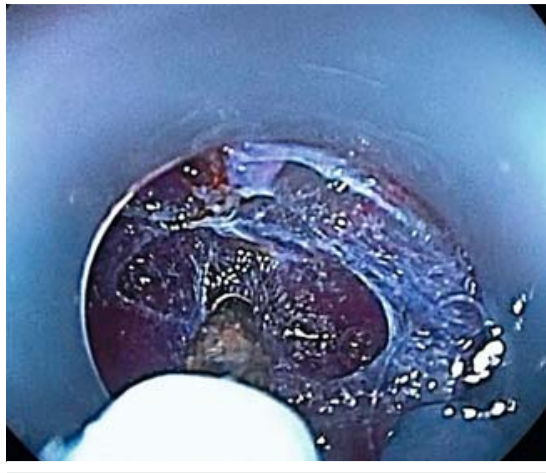

- Fig. 3 The submucosal tunnel created with a multifunctional snare (SOUTEN; Kaneka Medics, Tokyo, Japan).

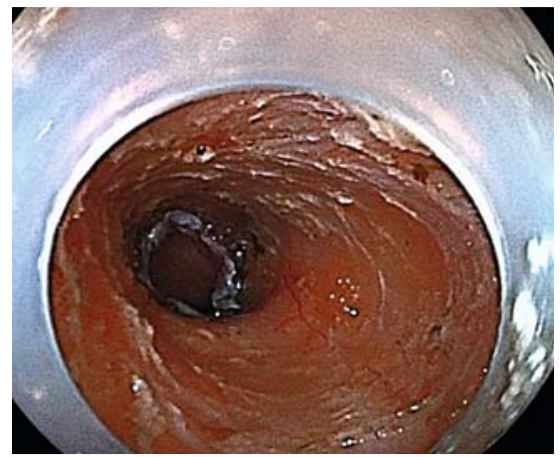

- Fig. 4 Endoscopic submucosal dissection was completed without any complications.
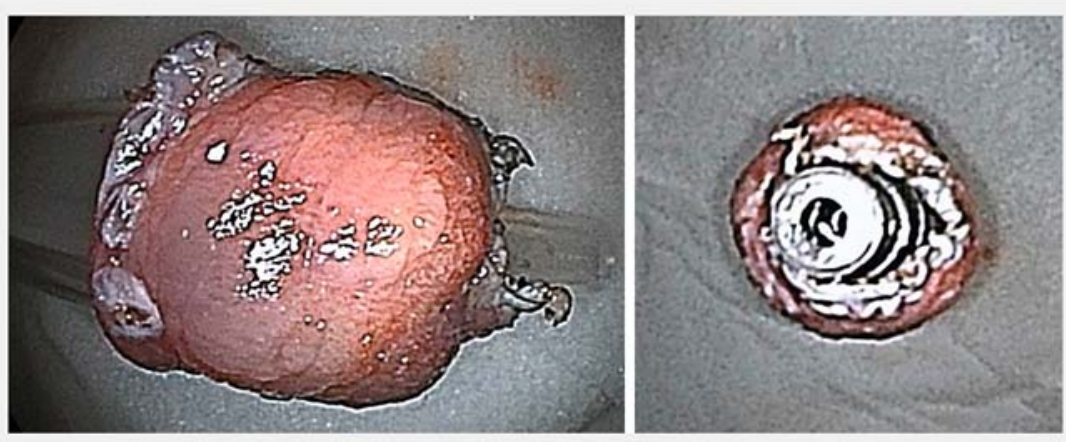

- Fig. 5 The complete circumferential resection specimen.

tunnel resection [5], which is a standard strategy for esophageal ESD, comprised the creation of a $10-\mathrm{mm}$ entry point proximal to the stenosis, and a submucosal tunnel ( $\vee$ Fig. 3 ); after penetration of the submucosal tunnel, the residual submucosa was resected ( $\mathbf{F i g . 4 , ~}>$ Video $\mathbf{1}$ ). The procedure was completed without complications ( $\triangleright$ Fig. 5 ).

Histological examination of the resected specimen revealed curative resection of squamous cell carcinoma.

The advantages of an SCE are its ability to enter the submucosal space easily and maintain fluent maneuverability in narrow spaces. An SCE and associated equipment are useful for ESD in cases with esophageal stenosis.

Endoscopy_UCTN_Code_TTT_1AO_2AG
The authors

Noriko Nishiyama ${ }^{1}$, Hideki Kobara ${ }^{1}$, Tatsuo Yachida ${ }^{1}$, Hirohito Mori ${ }^{1}$, Tingting Shi ${ }^{1}$, Keiich Okano $^{2}$, Tsutomu Masaki ${ }^{1}$

1 Department of Gastroenterology and Neurology, Faculty of Medicine, Kagawa University, Kagawa, Japan

2 Department of Gastroenterological Surgery, Faculty of Medicine, Kagawa University, Kagawa, Japan

\section{Corresponding author}

\section{Noriko Nishiyama, MD, PhD}

Department of Gastroenterology and Neurology, Faculty of Medicine, Kagawa University, 1750-1 Ikenobe, Kagawa 7610793, Japan

Fax: 81-87-8912158

n-nori@med.kagawa-u.ac.jp

\section{References}

[1] Shi Q, Ju H, Yao LQ et al. Risk factors for postoperative stricture after endoscopic submucosal dissection for superficial esophageal carcinoma. Endoscopy 2014; 46: $640-644$

[2] Yamamoto $\mathrm{Y}$, Kikuchi D, Uedo $\mathrm{N}$ et al. Management of adverse events related to endoscopic resection of upper gastrointestinal neoplasms: review of the literature and recommendations from experts. Dig Endosc 2019; 31: 4-20

[3] Nakamura M, Shiroeda H, Tahara T et al. Endoscopic submucosal dissection of an esophageal tumor using a transnasal endoscope without sedation. Endoscopy 2014; 46: E115-E116

[4] Kobara H, Mori H, Masaki T. Effective and economical endoscopic resection using a novel multifunctional snare for small-sized gastric neoplasms. Dig Endosc 2018; 30: $800-801$

[5] Arantes V, Albuquerque W, Dias CA et al. Standardized endoscopic submucosal tunnel dissection for management of early esophageal tumors (with video). Gastrointest Endosc 2013; 78: 946 - 952

Bibliography

DOI https://doi.org/10.1055/a-1011-3729

Published online: 27.9.2019

Endoscopy 2020; 52: E94-E95

(c) Georg Thieme Verlag KG

Stuttgart · New York

ISSN 0013-726X

\section{ENDOSCOPY E-VIDEOS}

https://eref.thieme.de/e-videos

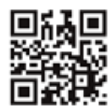

Endoscopy E-Videos is a free access online section, reporting on interesting cases and new techniques in gastroenterological endoscopy. All papers include a high quality video and all contributions are freely accessible online.

This section has its own submission website at

https://mc.manuscriptcentral.com/e-videos 